\title{
Changes in studying at Russian universities in the context of the COVID-19 pandemic
}

\author{
Lyudmila Nikolaevna Petrova ${ }^{1}$ \\ Plekhanov Russian University of Economics, Department of Foreign Languages No. 2, Moscow, \\ Russia
}

\begin{abstract}
The relevance of the study is due to the contradiction between the massive transition of Russian universities to a distance learning format and the insufficient readiness of participants in the educational process in the conditions of the COVID-19 pandemic. The situation with distance education before the pandemic was analyzed and the prerequisites for the emergence of problems and difficulties in the transition to online education were identified. An analysis of the difficulties faced by teachers and students of Russian higher educational institutions enabled to identify objective and subjective factors of their occurrence, as well as to develop recommendations for the further continuation of distance learning in combination with the traditional learning format. The purpose of the study is to analyze modern work experience in the conditions of the COVID-19 pandemic using the example of working with students of the Plekhanov Russian University of Economics. The analysis of successes and problems is conducted; the contradictions between distance and traditional forms of education are shown. The main models of organizing the studies are considered, which imply traditional and remote formats of studying using distance educational technologies. The works of various researchers, both Russian and foreign, on the problem of distance learning, are also analyzed. As a result of the study, it was concluded that in the modern education system of Russian higher educational institutions, distance education can be considered as a complementary and reinforcing form of the already existing traditional ("face to face") training format with its socio-pedagogical, organizational, and psychological-didactic potential. In the work, the methods of theoretical (analysis, synthesis, systematization, comparison) and empirical (study of literature, interview, questionnaire, observation) research were used in a comprehensive manner. The combination of forms of interaction in real and virtual space in learning in modern didactics should be considered as a general didactic principle of learning.
\end{abstract}

Keywords: distance learning, online learning, digitalization of education, learning models

\section{Introduction}

${ }^{1 *}$ Corresponding author: petrova.ln@rea.ru 
In the context of the COVID-19 pandemic, the entire educational system of Russia and the world was forced to transfer educational organizations to a remote form of organizing the educational process. Therefore, the country's universities found themselves in a fundamentally new situation, when the entire educational process was transferred to a remote format, which involved the use and application of distance learning technologies. If this situation is compared with previous modernizations and reforms of education [1], then this situation is different, due to the fact that, firstly, it covers the entire education system of Russia at all levels; secondly, due to the absolute unpredictability of the situation and the lack of any preparation for what happened; thirdly, due to the simultaneous transfer of all educational organizations to a qualitatively new format of education.

It should be noted here that in developed countries there is sufficient experience in organizing distance education using information and computer means of communications. There are two main directions: 1) online education, i.e., remote presentation of education via the Internet; 2) open education, i.e., creating open educational resources for non-formal education and presumably use in formal education [2, 3]

The rapid development of mobile and cloud technologies has contributed to the emergence of numerous scientific studies, as a result of which it becomes obvious that the integration of mobile technologies into the educational process can radically transform it [4]. For example, the integration of distance technologies helps to take into account the individual characteristics of students and allows them to work outside the classroom at any free time [5]. In addition, distance technologies create a mobile interactive learning environment and provide instant feedback, help to quickly and adequately solve numerous learning problems, help to create new types of presenting the material and new formats of interactive tasks based on applying the augmented reality and geolocation application [6].

For a long time, Russian universities have been working on introducing electronic educational resources, online courses on the required academic disciplines and levels of training into the educational system. There are numerous studies on the trends in the development of Russian education in the digital age [7-9], as well as on implementating online courses in the educational system of universities and the role and place of digital technologies [10-12].

All of the aforementioned theoretical and practical prerequisites led to a rather painless transition to the format of mass remote learning with the use of electronic educational resources.

However, a number of problems emerged in various aspects of the functioning and development of educational activities. The most difficult thing appeared to be organizing the collective activity itself, keeping the attention of students, as well as the asynchrony of emotional and intellectual moments of distance learning. It turned out that the accumulated experience in teaching with distance technologies was insufficient for organizing contact teaching using electronic information and educational environment and distance educational technologies. Here the contradiction can be mentioned between the large-scale and one-time transition of the entire educational system in universities to distance learning format, which required all its participants to change their approaches to its preparation and implementation and their insufficient readiness to work in this new format.

This leads to the main problem of the study: to determine the factors that prevent teachers and students from effectively interacting in the new format of distance learning.

Purpose of the study: based on the analysis of literature and the experience of distance learning (using the example of the Plekhanov Russian University of Economics), to identify the difficulties experienced by teachers and students of universities in the conditions of the COVID-19 pandemic and to determine the models of forms of study in the conditions of digitalization of education. 


\section{Results and discussion}

The fact that there has been a large-scale transfer of the higher educational system to the format of contact distance learning using distance learning technologies has revealed both great opportunities and limitations of online learning. The results of the study reveal that there is a risk of a decrease in the motivation for learning, the inherent value of knowledge is lost, as well as unification and primitivization of the content of learning and education are observed. In the course of distance learning, students try to choose the most popular online courses, which are prepared by leading experts in a particular field of knowledge. As a result, there is a loss of pluralism in approaches to the content of education. However, the fact that students see different approaches to the same phenomenon is very important in view of the increasing differentiation of knowledge. There are various opinions of different researchers in this regard. Thus, Rakitov believes that "the formalization of professional knowledge and a decrease in its diversity may, under certain conditions, negatively affect the practical activities of university graduates in the future" [13].

Kolesnikova focuses on the fact that with the digitalization of higher education, there is atomization, granulation of courses, and at the same time there is an amateurish approach to creating and teaching new disciplines. As a result, the quality of courses and the value-semantic logic of teaching the subject fades into the background. Along with targeted educational materials, games, social networks, open sites, and various applications become sources of knowledge, which leads to obtaining superficial knowledge, to the primitivization of the obtained information. As a result, "there is a shift in the ways of knowing the world - from theoretical comprehension to direct spontaneous action, not always conscious one... In the flow of spontaneous interaction with information, scientific facts and objective knowledge gradually lose their meaning" [7]. It should also be noted that the distance learning format requires not only high level of motivation from students, but also the ability to self-study and possession of the necessary skills. It should be noted that not every student can study independently, and most complex courses require this particular skill. According to the data, only $5-10 \%$ of distance learning students successfully complete their studies [7].

The possibilities of implementing the upbringing and developmental functions of education are significantly limited in the distance learning format. In the process of teaching, upbringing assumes an emotional-value attitude to situations of moral choice and implies that the student lives through the situation and experiences it on the basis of the acquired knowledge of the moral norms accepted in society. Verbitskii emphasizes that moral education should not be limited to assimilating information about what is considered good or bad in society. A poorly educated, immoral person, a criminal, a bribe-taker can know the norms of morality very well [10]. Due to the lack of live communication in distance learning and digital imitation of traditional courses, the problem of transferring implicit knowledge, which is inseparable from a person, arises [14].

Online learning technologies allow the student to quickly find the required information, avoid strenuous mental work, and also form the habit of looking for a quick answer on the Internet. As a result, the student loses the ability to perceive voluminous texts. There is a real risk of speech and thinking degradation as it begins to form before pressing a computer button. The lack of a developed practice of live communication with the formation and formulation of thought and speech contributes to the lack of thinking [10]. A researcher from Japan Matasaka notes that "although mobile technologies have freed us from a whole kind of everyday difficulties, they now weaken us and destroy us ... people will gradually lose the ability to think" [15].

Modern researchers pay attention to such questions and problems. It is worth noting that they were already mentioned before the pandemic, when in some universities online 
education was already in its pure form, or it was in separate programs or courses within the framework of formal higher education, or in supplementary general and vocational education.

Now it is suggested to move on to considering the conclusions of the experience of work in the Plekhanov Russian University of Economics in the conditions of the COVID-19 pandemic. First of all, the question of the attitude of teachers and students to distance learning was of interest for the research.

Table 1 summarizes the data of a survey of students and teachers, working and studying at the Plekhanov Russian University of Economics.

Table 1. Survey data.

\begin{tabular}{|l|l|l|}
\hline Questions & Answers & Digital data processing \\
\hline 1. Are you satisfied with the & In general, yes & $41.2 \%$ \\
organization of distance & Rather yes & $43.4 \%$ \\
learning? & Rather no & $15.4 \%$ \\
\hline $\begin{array}{l}\text { 2. How convenient is distance } \\
\text { education for you? }\end{array}$ & Very convenient & $36.8 \%$ \\
& Convenient, but face-to-face & \\
& consultations with a teacher are & \\
& required & $28 \%$ \\
& Not very convenient & $30.3 \%$ \\
& Totally unacceptable & $5 \%$ \\
\hline 3. Would you like the elements & Yes & $30.4 \%$ \\
of distance learning to be used & Rather yes & $29.1 \%$ \\
after the end of the pandemic? & Rather no & $17.5 \%$ \\
& Definitely not & $14.3 \%$ \\
& Hard to answer & $8.7 \%$ \\
\hline 4. Please describe your mood in & The state of health and mood has & \\
relation to the full transition to & not changed & $37.6 \%$ \\
distance learning & The mood and state of health & $35 \%$ \\
& have improved & $24.2 \%$ \\
& Complete discomfort & $29.2 \%$ \\
\hline
\end{tabular}

From the data presented in the table, it follows that the majority of students, $85 \%$, are generally satisfied with the organization of distance learning during the COVID-19 pandemic. Practical sessions were held in Zoom, lectures - on the Webinar platform, exams and credits - in Zoom, Webinar, and Moodle. Sessions of the department, planning meetings, and conferences were held in Zoom. All this suited the students and teachers, since this is a noticeable gain in time (it is possible to connect at any convenient place - in the office, at home, in the countryside, etc.) However, students and teachers also noted problems: the lack of the Internet, insufficient control over the conduct of classes by the teacher, etc.

Discomfort in answering the second question is mainly due to the lack of "face-to-face" communication, as well as the lack of skills for self-discipline and self-organization.

The answers to the third question indicate that the majority of students and teachers, $59.5 \%$, want distance learning elements to be used after the pandemic.

According to the analysis of the answers to the fourth question, it can be stated that the mood during distance learning is associated with two types of problems - technical and technological (lack of the Internet, being knocked out of Zoom, inability to use these platforms) and organizational and pedagogical (the student cannot concentrate, be self-organized at home, the teacher cannot explain, direct). Among the problems students also noted an increase in the volume of homework, and teachers - an increase in the time for organizing work and checking students' works. 
In general, on the basis of the survey, three models of possible learning in the post-pandemic can be distinguished - the first is the traditional model of distance learning, which involves remote learning based on digital information and educational environment (conducted in an asynchronous mode). Essentially, this is traditional extramural training.

The second model is contact distance learning using the electronic educational environment of the university (synchronous mode).

The third model is blended learning, where a combination of distance and traditional formats is possible. It should be noted that this model seems to be the most effective and practical on the basis of a survey of students and teachers and on the basis of the authors' own work experience during the pandemic.

\section{Conclusion}

The COVID-19 pandemic undoubtedly caused a number of changes in learning at Russian higher educational institutions; it revealed and identified various problems and shortcomings of both the traditional format of education in universities, as well as the distance learning. In addition, there is an awakening of a huge and large-scale socio-pedagogical experimental work, the new factor of which is the introduction of the contact distance learning using the electronic educational environment of the university and distance educational technologies into the learning process.

The analysis of the attitude to distance learning of students and teachers suggests that in the system of basic education, training at a university can be considered as a reinforcing and complementary form of socio-pedagogical, organizational, psychological and prospective potential of the traditional learning format. In the system of modern education of Russian higher educational institutions, a combination of forms, methods and means of traditional and distance dialogue between participants in the educational process is required. Hence the conclusion that in the combination of forms of interaction between real and virtual space in modern didactics, it is required to consider the general didactic principle of learning, which is aimed at implementing and identifying the psychological and pedagogical capabilities of the information and educational environment and distance educational technologies in the education system of Russian universities.

\section{References}

1. N.V. Afanasev, et al., Amaz. Invest. 8(22), 658-664 (2019)

2. D.G. Kochergin, E.E. Zhernov, Prof. Edu. Rus. Abroad 2(34), 12-23 (2019)

3. L. Yuan, S. Powell, eLearning Papers, In-Depth, 33(2), 1-7 (2013)

4. A. Kukulska-Hulme, Mobile learning for quality education and social inclusion. Accessed on: July 17, 2021. [Online]. Available: https://iite.unesco.org/files/policy_briefs/pdf/en/mobile_learning.pdf

5. J. Traxler, Int. J. Mob. Blend. Learn. 1(1), 1-12 (2009). https://doi.org/10.4018/jmbl.2009010101

6. P. Driver, Int. J. Comp. Assist. Lang. Learn. Teach. 2(4), 23-37 (2012). https://doi.org/10.4018/ijcallt.2012100104

7. I.A. Kolesnikova, Higher Edu. Rus. 28(8-9), 67-83 (2019). https://doi.org/10.31992/0869-3617-2019-28-8-9-67-82

8. G.F. Shafranov-Kutsev, Bul. Tyumen State Univ. Soc.-Econ. Legal Res. 3(4), 8-18 (2017) 
9. G.L. Tulchinskii, Philos. Sci. (6), 121-136 (2017)

10. A.A. Verbitskii, Homo Cyb. 1(6) (2019)

11. M.F. Galikhanov, G.F. Khasanova, Higher Edu. Rus. 28(2), 51-62 (2019). https://doi.org/10.31992/0869-3617-2019-28-2-51-62

12. A.Ya. Danilyuk, A.A. Faktorovich, Tsifrovoe obshchee obrazovanie [Digital general education] (Avtorskaya masterskaya, Moscow, 2019)

13. A.I. Rakitov, Higher Edu. Rus. 27(6), 41-49 (2018)

14. A.S. Robotova, Higher Edu. Rus., 10, 152-156 (2019). https://doi.org/10.31992/0869-3617-2019-28-10-152-156

15. Yu.V. Novakovskaya, Bul. Moscow Univ. Pedag. Edu., 1, 13-30 (2013) 